\title{
Genome sequence of the phage-gene rich marine Phaeobacter arcticus type strain DSM 23566 ${ }^{\mathrm{T}}$
}

\author{
Heike M. Freese ${ }^{1}$, Hajnalka Dalingault ${ }^{2}$, Jörn Petersen ${ }^{1}$, Silke Pradella ${ }^{1}$, Karen Davenport ${ }^{2}$, \\ Hazuki Teshima ${ }^{2}$, Amy Chen ${ }^{3}$, Amrita Pati ${ }^{4}$, Natalia Ivanova ${ }^{4}$, Lynne A. Goodwin ${ }^{2,4}$, Patrick \\ Chain $^{2}$, John C. Detter ${ }^{2,4}$, Manfred Rohde ${ }^{5}$, Sabine Gronow ${ }^{1}$, Nikos C. Kyrpides ${ }^{4}$, Tanja \\ Woyke $^{4}$, Thorsten Brinkhoff ${ }^{6}$, Markus Göker ${ }^{1 *}$, Jörg Overmann', Hans-Peter Klenk1 \\ ${ }^{1}$ Leibniz Institute DSMZ - German Collection of Microorganisms and Cell Cultures, \\ Braunschweig, Germany \\ ${ }^{2}$ Los Alamos National Laboratory, Bioscience Division, Los Alamos, New Mexico, USA \\ ${ }^{3}$ Biological Data Management and Technology Center, Lawrence Berkeley National \\ Laboratory, Berkeley, California, USA \\ ${ }^{4}$ DOE Joint Genome Institute, Walnut Creek, California, USA \\ ${ }^{5}$ HZI - Helmholtz Centre for Infection Research, Braunschweig, Germany \\ ${ }^{6}$ Institute for Chemistry and Biology of the Marine Environment, Oldenburg, Germany \\ * Corresponding author: markus.goeker@dsmz.de
}

Keywords: aerobic, psychrophilic, motile, high-quality draft, prophage-like structures, extrachromosomal elements, assimilatory nitrate reduction, Alphaproteobacteria,

Roseobacter clade

Phaeobacter arcticus Zhang et al. 2008 belongs to the marine Roseobacter clade whose members are phylogenetically and physiologically diverse. In contrast to the type species of this genus, Phaeobacter gallaeciensis, which is well characterized, relatively little is known about the characteristics of $P$. arcticus. Here, we describe the features of this organism including the annotated high-quality draft genome sequence and highlight some particular traits. The 5,049,232 bp long genome with its 4,828 protein-coding and 81 RNA genes consists of one chromosome and five extrachromosomal elements. Prophage sequences identified via PHAST constitute nearly $5 \%$ of the bacterial chromosome and included a potential Mu-like phage as well as a gene-transfer agent (GTA). In addition, the genome of strain DSM $23566^{\top}$ encodes all of the genes necessary for assimilatory nitrate reduction. Phylogenetic analysis and intergenomic distances indicate that the classification of the species might need to be reconsidered.

\section{Introduction}

Strain 20188 ${ }^{\mathrm{T}}$ DSM $23566^{\mathrm{T}}=$ CGMCC $1.6500^{\mathrm{T}}=$ JCM 14644T) is the type strain of Phaeobacter arcticus, a marine member of the Rhodobacteraceae (Rhodobacterales, Alphaproteobacteria) [1] which belongs to the Roseobacter clade, a phylogenetically and physiologically diverse group. Strain 20188 was isolated from marine sediment of the Arctic Ocean (at $75^{\circ} 00^{\prime} 24^{\prime \prime} \mathrm{N}$ and $169^{\circ} 59^{\prime} 37^{\prime \prime} \mathrm{W}$ ) from a water depth of $167 \mathrm{~m}$. The species epithet is derived from the Latin adjective arcticus (= northern, arctic), referring to the site from where the strain was isolated. PubMed records do not indicate any follow-up research with strain $20188^{\mathrm{T}}$ after its initial description and the valid publication of the new species name $P$. arcticus [1]. A few additional strains have been isolated and 16S rRNA gene sequenced (NCBI database), but no additional information on these strains is available so far. As a con- sequence, little is known regarding the physiology or distinguishing characteristics of $P$. arcticus. Here we present a summary classification and a set of features for $P$. arcticus DSM 23566 ${ }^{\mathrm{T}}$, together with the description of the high-quality permanent draft genome sequence and annotation, including insights into extrachromosomal elements, prophagelike structures as well as evidence for inorganic nitrogen assimilation.

\section{Classification and features}

$16 S$ rRNA analysis

A representative genomic $16 \mathrm{~S}$ rRNA gene sequence of $P$. arcticus DSM $23566^{\mathrm{T}}$ was compared using NCBI BLAST [2,3] under default settings (e.g., considering only the high-scoring segment pairs (HSPs) from the best 250 hits) with the most recent release of the Greengenes database [4]. The relative 
frequencies of taxa and keywords (reduced to their stem [5]) were determined, weighted by BLAST scores. The most frequently occurring genera were Phaeobacter (46.4\%), Roseobacter (24.9\%), Ruegeria (6.1\%), Paracoccus (5.4\%) and Leisingera (4.4\%) (91 hits in total). Regarding the nine hits to sequences from other members of the genus, the average identity within HSPs was $97.1 \%$, whereas the average coverage by HSPs was $99.5 \%$. Among all other species, the one yielding the highest score was 'marine bacterium ATAM407_56' isolated from a culture of Alexandrium tamarense AF359535, which corresponded to an identity of $99.4 \%$ and an HSP coverage of $99.9 \%$ (Note that the Greengenes database uses the INSDC (= EMBL/NCBI/DDBJ) annotation, which is not an authoritative source for nomenclature or classification). The highestscoring environmental sequence was EU287348 (Greengenes short name 'Pacific arctic surface sed- iment clone S26-48'), which showed an identity of $99.9 \%$ and an HSP coverage of $100.0 \%$. The most frequently occurring keywords within the labels of all environmental samples which yielded hits were 'marin' (5.6\%), 'water' (5.5\%), 'microbi' (4.5\%), 'ocean' (4.5\%) and 'coastal' (4.1\%) (156 hits in total). The most frequently occurring keywords within the labels of those environmental samples which yielded hits of a higher score than the highest scoring species was 'arctic, pacif, sediment, surfac' $(25.0 \%)$ (1 hit in total). These hits correspond to the known ecology of $P$. arcticus $20188^{\mathrm{T}}$, which was isolated from marine sediment of the Arctic Ocean.

The phylogenetic neighborhood of $P$. arcticus is shown in Figure 1 in a 16S rRNA gene tree. The sequences of the five $16 \mathrm{~S}$ rRNA gene copies in the genome do not differ from each other, and differ by one nucleotide from the previously published $16 \mathrm{~S}$ rDNA sequence DQ514304.

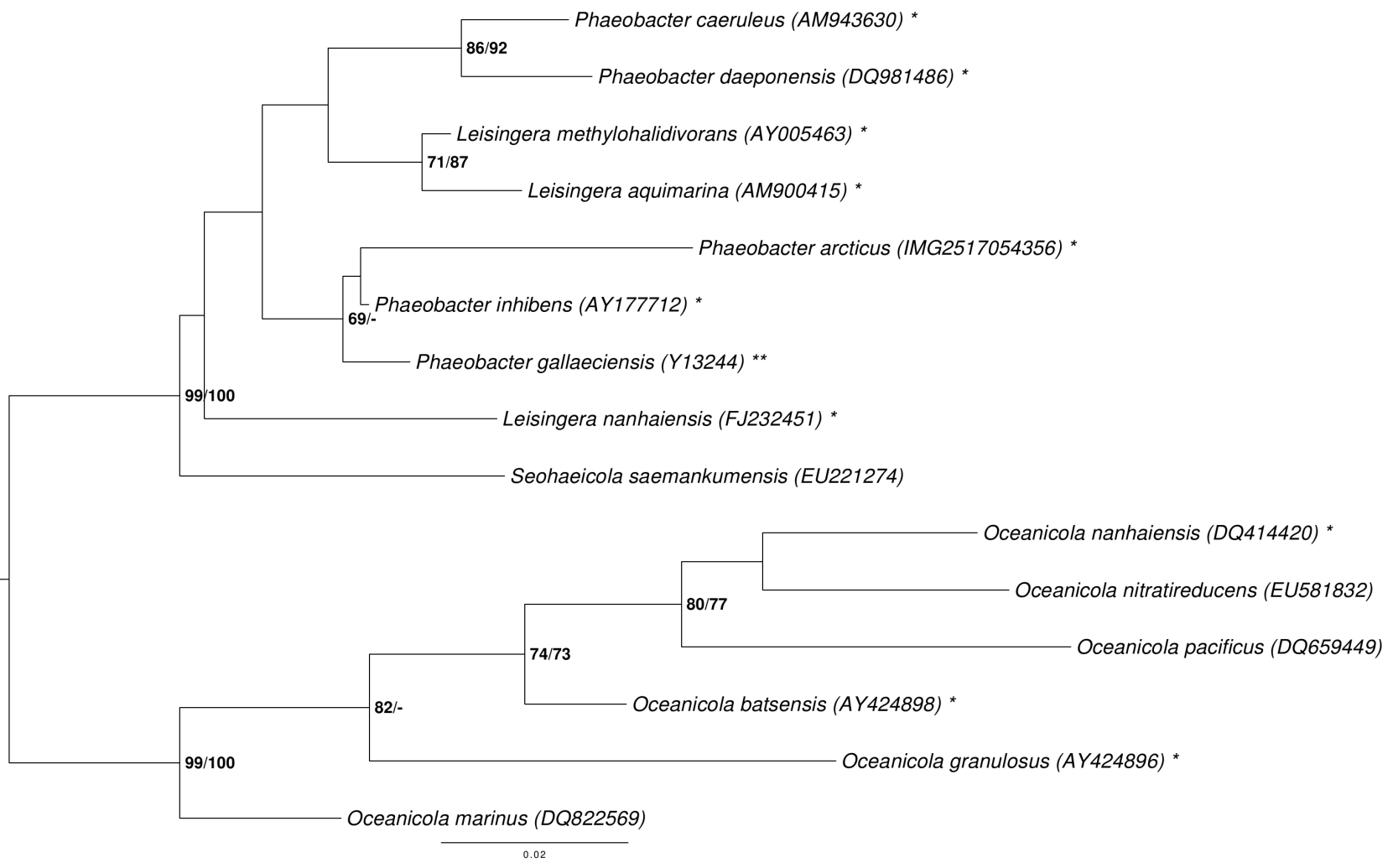

Figure 1. Phylogenetic tree highlighting the position of $P$. arcticus relative to the type strains of the other species within the genus Phaeobacter and neighboring genera such as Leisingera. The tree was inferred from 1,385 aligned characters [6,7] of the 16S rRNA gene sequence under the maximum likelihood (ML) criterion [8]. Oceanicola species were included in the dataset as outgroup taxa. The branches are scaled in terms of the expected number of substitutions per site. Numbers adjacent to the branches are support values from 1,000 ML bootstrap replicates [9] (left) and from 1,000 maximum-parsimony bootstrap replicates [10] (right) if larger than $60 \%$. Lineages with type-strain genome sequencing projects registered in GOLD [11] are labeled with one asterisk, those also listed as 'Complete and Published' with two asterisks [12]. Two novel genome sequences were published in this issue $[58,59]$. 


\section{Morphology and physiology}

The cells of strain $20188^{\mathrm{T}}$ are motile rods with a width of 0.3 to $0.5 \mu \mathrm{m}$ and a length of 1.0 to $2.6 \mu \mathrm{m}$ (Figure 2, Table 1, [1]). Star-shaped cell aggregates occur (Figure 2). Colonies are circular and yellow. Growth occurs under psychrophilic, chemoheterotrophic and aerobic conditions and between $0^{\circ} \mathrm{C}$ and $25^{\circ} \mathrm{C}$ with an optimum growth rate at $19-20^{\circ} \mathrm{C}$. No growth is observed at temperatures above $37^{\circ} \mathrm{C}$ [1]. Optimal $\mathrm{pH}$ for growth is approximately $\mathrm{pH}$ 6.0-9.0 (total range $\mathrm{pH}$ 5.010.0 ), and growth occurs within a salinity range of $2 \%$ to $9 \% \mathrm{NaCl}$, but not in the absence of $\mathrm{NaCl}$ [1]. Several carbohydrates like glucose, glycerol, fructose, melezitose, L-arabinose, D-mannose, mannitol, gluconate, $\mathrm{N}$-acetylglucosamine and malate are utilized as sole carbon source, whereas sucrose, lactose, galactose, trehalose and cellobiose but also leucine, serine and L-glutamate cannot be utilized as sole carbon sources [1]. Strain $20188^{\mathrm{T}}$ produces acid from glucose and glycerol. Further metabolic traits are listed elsewhere [1].

\section{Chemotaxonomy}

Ubiquinone-10 was found as major respiratory quinone, which is a common feature in most Alphaproteobacteria. The spectrum of main polar lipids in strain 20188 ${ }^{\mathrm{T}}$ consisted of phosphatidylethanolamine, phosphatidylglycerol, phosphatidylcholine and an unidentified aminolipid [1]. The major fatty acids are the monounsaturated fatty acids $\mathrm{C}_{18: 1 \omega 7 \mathrm{c}}(44.63 \%)$ and 11 methyl $\mathrm{C}_{18: 1 \omega 7 \mathrm{c}}(18.10 \%)$, followed by an unknown fatty acid (equivalent chain-length (ECL) of 11.799; $10.88 \%), \mathrm{C}_{16: 0}(9.69 \%)$, some hydroxyl fatty acids $\mathrm{C}_{10: 0}$ 3-он $(6.75 \%), \mathrm{C}_{16: 0}$ 2-ОH $(3.95 \%)$, iso- $\mathrm{C}_{15: 0} 2-\mathrm{OH}$ and/or $\mathrm{C}_{16: 1 \omega 7 \mathrm{c}}(2.30 \%)$, as well as traces of $\mathrm{C}_{15: 0}$, $\mathrm{C}_{12: 0}, \mathrm{C}_{18: 12-\mathrm{OH}}$ and $\mathrm{C}_{18: 0}$ [1]. The presence of photosynthetic pigments has not been tested.

\section{Genome sequencing and annotation Genome project history}

This organism was selected for sequencing on the basis of the DOE Joint Genome Institute Community Sequencing Program 2010, CSP 441: "Whole genome type strain sequences of the genera Phaeobacter and Leisingera - a monophyletic group of physiologically highly diverse organisms". The genome project is deposited in the Genomes On Line Database [11] and the complete genome sequence is deposited in GenBank. Sequencing, finishing and annotation were performed by the DOE Joint Genome Institute (JGI). A summary of the project information is shown in Table 2.

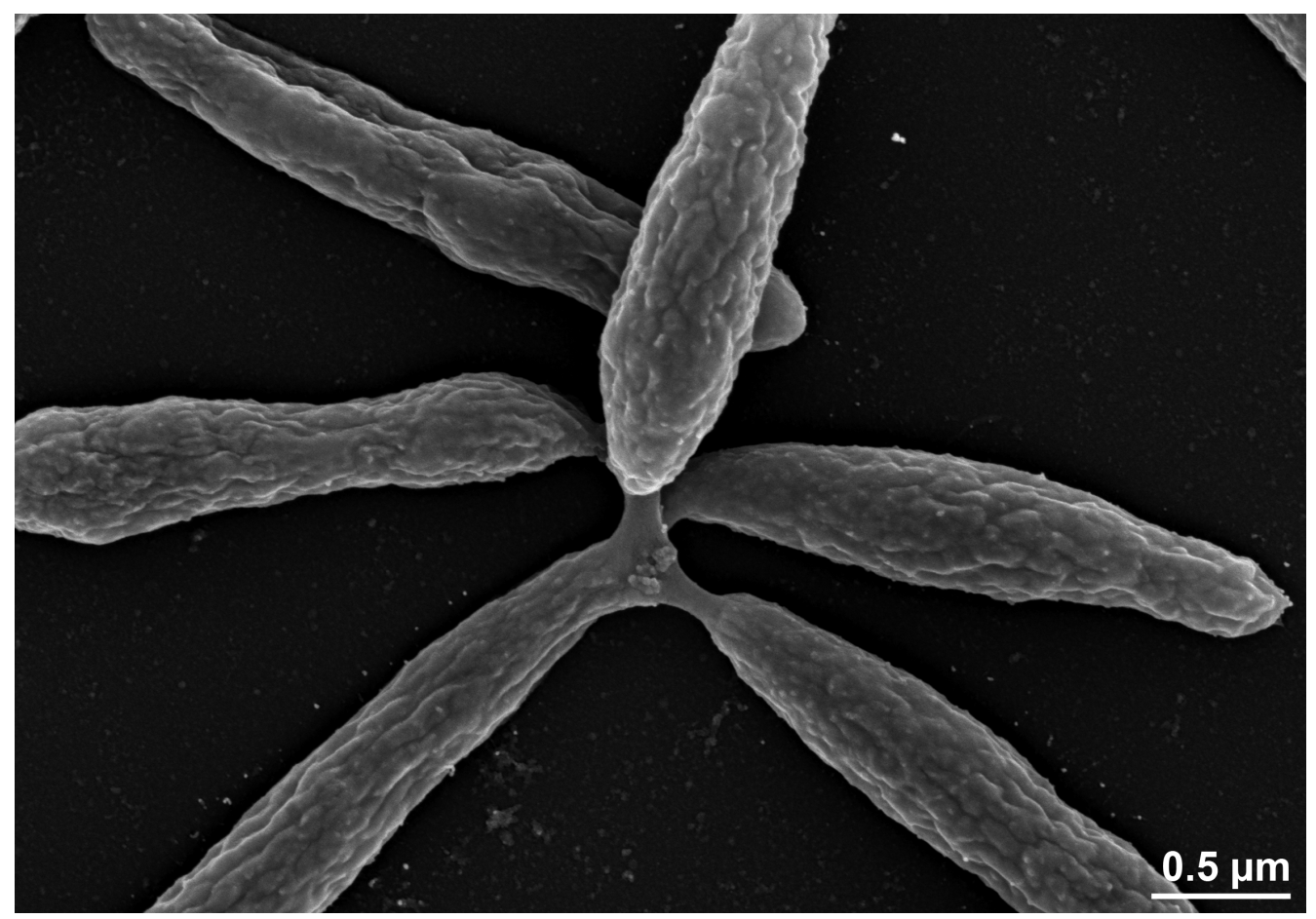

Figure 2. Scanning electron micrograph of $P$. arcticus DSM $23566^{\top}$ 
Table 1. Classification and general features of $P$. arcticus DSM 23566 according to the MIGS recommendations [13].

\begin{tabular}{|c|c|c|c|}
\hline MIGS ID & Property & Term & Evidence code \\
\hline & & Domain Bacteria & TAS [14] \\
\hline & & Phylum Proteobacteria & TAS [15] \\
\hline & & Class Alphaproteobacteria & TAS $[16,17]$ \\
\hline & Current classification & Order Rhodobacterales & TAS $[16,18]$ \\
\hline & & Family Rhodobacteraceae & TAS $[16,19]$ \\
\hline & & Genus Phaeobacter & TAS $[20,21]$ \\
\hline & Species & Species Phaeobacter arcticus & TAS [1] \\
\hline MIGS-12 & Reference for biomaterial & Zhang et al. 2008 & TAS [1] \\
\hline \multirow[t]{8}{*}{ MIGS-7 } & Subspecific genetic lineage (strain) & $20188^{\top}$ & TAS [1] \\
\hline & Gram stain & Gram-negative & TAS [1] \\
\hline & Cell shape & rod-shaped & TAS [1] \\
\hline & Motility & motile & TAS [1] \\
\hline & Sporulation & not reported & \\
\hline & Temperature range & $0-25^{\circ} \mathrm{C}$, psychrophile & TAS [1] \\
\hline & Optimum temperature & $19-20^{\circ} \mathrm{C}$ & TAS [1] \\
\hline & Salinity & $2-9 \%(w / v) \mathrm{NaCl}$ & TAS [1] \\
\hline \multirow[t]{3}{*}{ MIGS-22 } & Relationship to oxygen & aerobe & TAS [1] \\
\hline & Carbon source & glucose; glycerol, mannitol, gluconate, malate & TAS [1] \\
\hline & Energy metabolism & chemoheterotrophic & TAS [1] \\
\hline MIGS-6 & Habitat & marine sediment & TAS [1] \\
\hline MIGS-6.2 & $\mathrm{pH}$ & 5.0-10.0, optimum 6.0-9.0 & TAS [1] \\
\hline MIGS-15 & Biotic relationship & not reported & \\
\hline MIGS-14 & Known pathogenicity & none & IDA \\
\hline MIGS-16 & Specific host & not reported & \\
\hline \multirow[t]{2}{*}{ MIGS-18 } & Health status of host & not reported & \\
\hline & Biosafety level & 1 & TAS [22] \\
\hline MIGS-19 & Trophic level & heterotroph & TAS [1] \\
\hline MIGS-23.1 & Isolation & marine sediment & TAS [1] \\
\hline MIGS-4 & Geographic location & Arctic Ocean & TAS [1] \\
\hline MIGS-5 & Time of sample collection & August 2003 & TAS [1] \\
\hline MIGS-4.1 & Latitude & 75.01 & TAS [1] \\
\hline MIGS-4.2 & Longitude & -169.99 & TAS [1] \\
\hline MIGS-4.3 & Depth & $167 \mathrm{~m}$ & TAS [1] \\
\hline MIGS-4.4 & Altitude & $167 \mathrm{~m}$ & NAS \\
\hline
\end{tabular}

Evidence codes - IDA: Inferred from Direct Assay; TAS: Traceable Author Statement (i.e., a direct report exists in the literature); NAS: Non-traceable Author Statement (i.e., not directly observed for the living, isolated sample, but based on a generally accepted property for the species, or anecdotal evidence). Evidence codes are from the Gene Ontology project [60]. 


\begin{tabular}{lll}
\hline \multicolumn{2}{l}{ Table 2. Genome sequencing project } & information \\
\hline MIGS ID & Property & Term \\
\hline MIGS-31 & Finishing quality & permanent draft \\
MIGS-28 & Libraries used & One Illumina Standard (short PE) library, one Illumina CLIP (long PE) library \\
MIGS-29 & Sequencing platforms & Illumina GAii, PacBio \\
MIGS-31.2 & Sequencing coverage & Illumina $739 \times$ \\
MIGS-30 & Assemblers & Allpaths version r39750, Velvet 1.1.05, phrap version SPS - 4.24 \\
MIGS-32 & Gene calling method & Prodigal 1.4, GenePRIMP \\
& INSDC ID & pending \\
& GenBank Date of Release & Pending \\
& GOLD ID & Gi10722 \\
& NCBI project ID & 81437 \\
& Database: IMG & 2516653081 \\
Source material identifier & DSM 23566 \\
& Project relevance & Tree of Life, carbon cycle, sulfur cycle, environmental \\
\hline
\end{tabular}

\section{Growth conditions and DNA extractions}

A culture of DSM $23566^{\mathrm{T}}$ was grown in DSMZ medium 514 (Bacto Marine Broth) [23] at $20^{\circ} \mathrm{C}$. gDNA was purified using Jetflex Genomic DNA Purification Kit (GENOMED 600100) following the directions provided by the supplier but modified by the addition of $20 \mu$ l Proteinase $\mathrm{K}$ for cell lysis. The purity, quality and size of the bulk gDNA preparation were assessed by JGI according to DOE-JGI guidelines. DNA is available through the DNA Bank Network [24].

\section{Genome sequencing and assembly}

The draft genome sequence was generated using Illumina data [25]. For this genome, we constructed and sequenced an Illumina short-insert pairedend library with an average insert size of $247 \pm 59$ bp which generated 16,028,960 reads and an Illumina long-insert paired-end library with an average insert size of 8,186 $\pm 3,263$ bp which generated 9,112,084 reads totaling 3,771 Mbp of data (Feng Chen, unpublished). All general aspects of library construction and sequencing can be found at the JGI web site [26]. The initial draft assembly contained 20 contigs in 12 scaffolds. The initial draft data were assembled with Allpaths [27], version 39750, and the consensus was computationally shredded into $10 \mathrm{Kbp}$ overlapping fake reads (shreds). The Illumina draft data were also assembled with Velvet [28], and the consensus sequences were computationally shredded into 1.5 Kbp overlapping fake reads (shreds). The Illumina draft data were assembled again with Velvet using the shreds from the first Velvet assembly to guide the next assembly. The consensus from the second Velvet assembly was shredded into $1.5 \mathrm{Kbp}$ overlapping fake reads. The fake reads from the Allpaths assembly and both Velvet assemblies and a subset of the Illumina CLIP paired-end reads were assembled using parallel phrap (High Performance Software, LLC). Possible mis-assemblies were corrected with manual editing in Consed [29-31]. Gap closure was accomplished using repeat resolution software (Wei Gu, unpublished), and sequencing of bridging PCR fragments with Sanger and/or PacBio (Cliff Han, unpublished) technologies. A total of 13 PCR PacBio consensus sequences were completed to close gaps and to raise the quality of the final sequence. The final assembly is based on 3,771 Mbp of Illumina draft data, which provides an average $739 \times$ coverage of the genome.

\section{Genome annotation}

Genes were identified using Prodigal [32] as part of the JGI genome annotation pipeline [33], followed by a round of manual curation using the JGI GenePRIMP pipeline [34]. The predicted CDSs were translated and used to search the National Center for Biotechnology Information (NCBI) nonredundant database, UniProt, TIGR-Fam, Pfam, PRIAM, KEGG, COG, and InterPro databases. Additional gene prediction analysis and functional annotation was performed within the Integrated Microbial Genomes - Expert Review (IMG-ER) platform [35]. 


\section{Genome properties}

The genome statistics are provided in Table 3 and Figure 3. The genome consists of a 4,215,469 bp long chromosome (cArct_4215) and five extrachromosomal elements with $279,891 \mathrm{bp}$, 228,923 bp, 203,324 bp, 92,209 bp and 29,416bp length, respectively (pArct_A280 - pArct_E29), with a $\mathrm{G}+\mathrm{C}$ content of $59.3 \%$ (Table 3 and Figure 3 ). The identification of the scaffolds as chromosome and as extrachromosomal elements is explained below. Of the 4,909 genes predicted, 4,828 were protein-coding genes, and 81 RNAs; 102 pseudogenes were also identified. Although the five 16S rRNA gene copies in the genome were identical, one of the adjacent 16S-23S rRNA gene internal transcribed spacer (ITS) differs in five nucleotides from the four other copies. The majority of the protein-coding genes $(77.7 \%)$ were assigned a putative function while the remaining ones were annotated as hypothetical proteins. The distribution of genes into COGs functional categories is presented in Table 4.

Table 3. Genome Statistics

\begin{tabular}{lrr}
\hline Attribute & Value & \% of Total \\
\hline Genome size (bp) & $5,049,232$ & 100.00 \\
DNA coding region (bp) & $4,429,124$ & 87.72 \\
DNA G+C content $(b p)$ & $2,992,500$ & 59.27 \\
Number of replicons & 6 & \\
Extrachromosomal elements & 5 & \\
Total genes & 4,909 & 100.00 \\
RNA genes & 81 & 1.65 \\
rRNA operons & 5 & 1.20 \\
tRNA genes & 59 & 98.35 \\
Protein-coding genes & 4,828 & 2.08 \\
Pseudo genes & 102 & 77.69 \\
Genes with function prediction & 3,814 & 39.66 \\
Genes in paralog clusters & 1,947 & 76.49 \\
Genes assigned to COGs & 3,755 & 81.67 \\
Genes assigned Pfam domains & 4,009 & 33.63 \\
Genes with signal peptides & 1,651 & 20.86 \\
Genes with transmembrane helices & 1,024 & \\
CRISPR repeats & 0 &
\end{tabular}

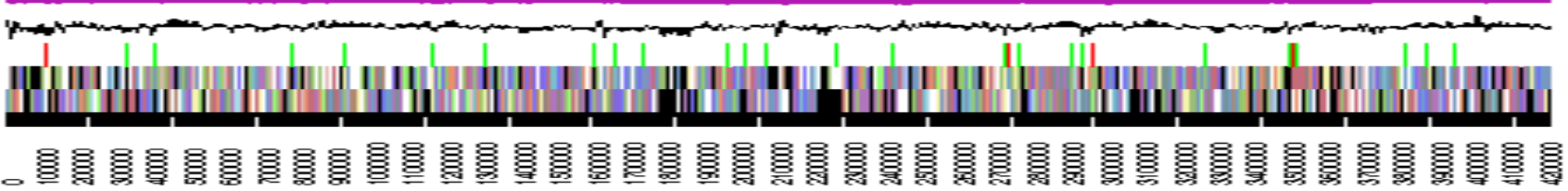

Figure 3a. Graphical map of the Phaeobacter arcticus DSM 23566 ${ }^{\top}$ chromosome cArct_4215. From bottom to the top: Genes on forward strand (color by COG categories), Genes on reverse strand (color by COG categories), RNA genes (tRNAs green, rRNAs red, other RNAs black), GC content, GC skew. 


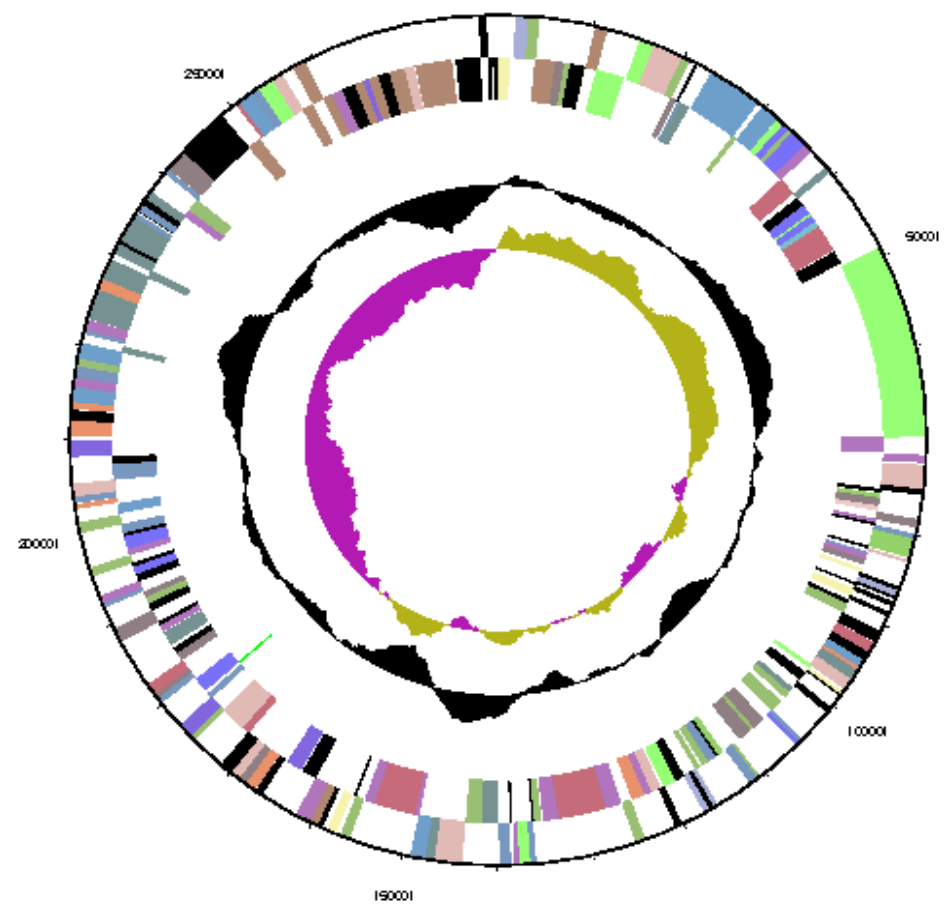

Figure 3b. Graphical map of the Phaeobacter arcticus DSM 23566. extrachromosomal element pArct_A280. From outside to the center: Genes on forward strand (color by COG categories), Genes on reverse strand (color by COG categories), RNA genes (tRNAs green, rRNAs red, other RNAs black), GC content, GC skew.

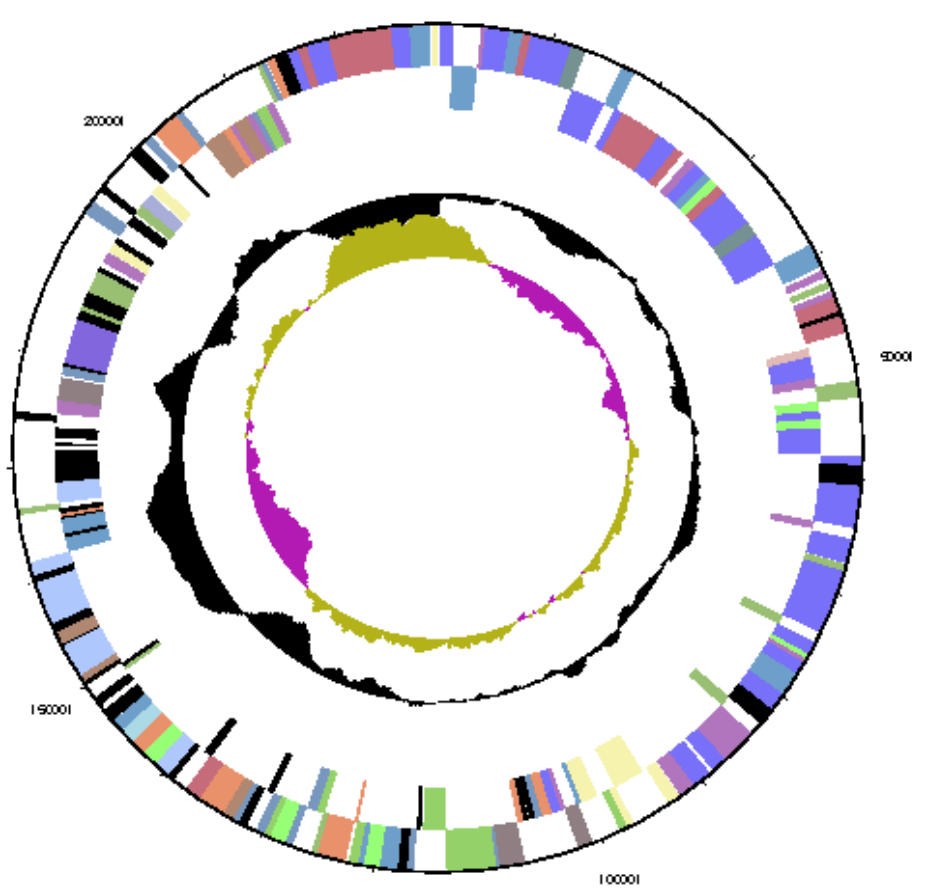

Figure 3c. Graphical map of the Phaeobacter arcticus DSM 23566' extrachromosomal element pArct_B229. From outside to the center: Genes on forward strand (color by COG categories), Genes on reverse strand (color by COG categories), RNA genes (tRNAs green, rRNAs red, other RNAs black), GC content, GC skew. 

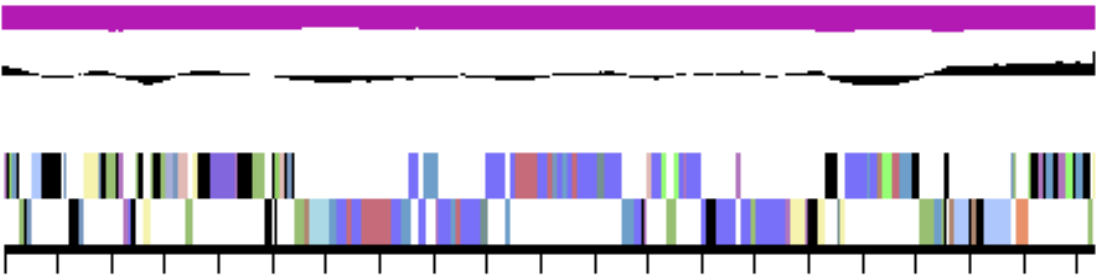

$\circ$

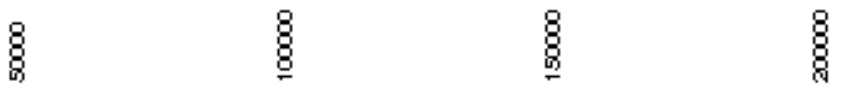

Figure 3d. Graphical map of the Phaeobacter arcticus DSM 23566 extrachromosomal element pArct_C203. From bottom to the top: Genes on forward strand (color by COG categories), Genes on reverse strand (color by COG categories), RNA genes (tRNAs green, rRNAs red, other RNAs black), GC content, GC skew.

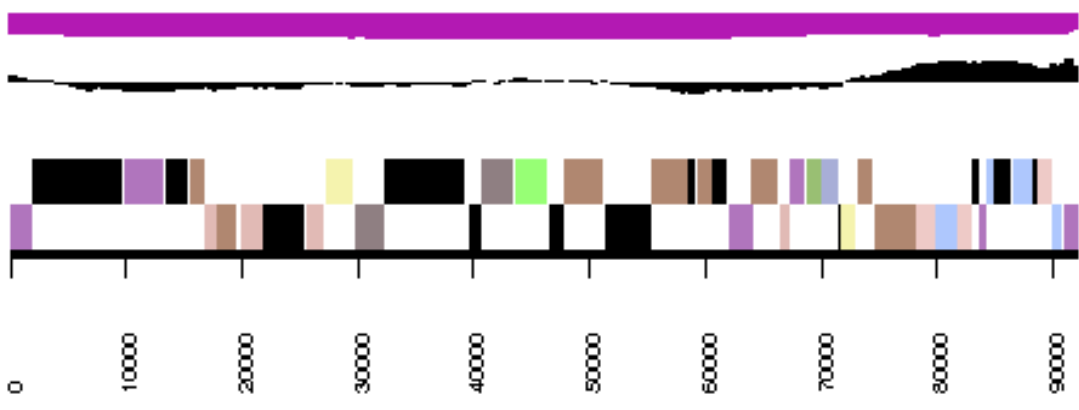

Figure 3e. Graphical map of the Phaeobacter arcticus DSM 23566 extrachromosomal element pArct_D92. From bottom to the top: Genes on forward strand (color by COG categories), Genes on reverse strand (color by COG categories), RNA genes (tRNAs green, rRNAs red, other RNAs black), GC content, GC skew.

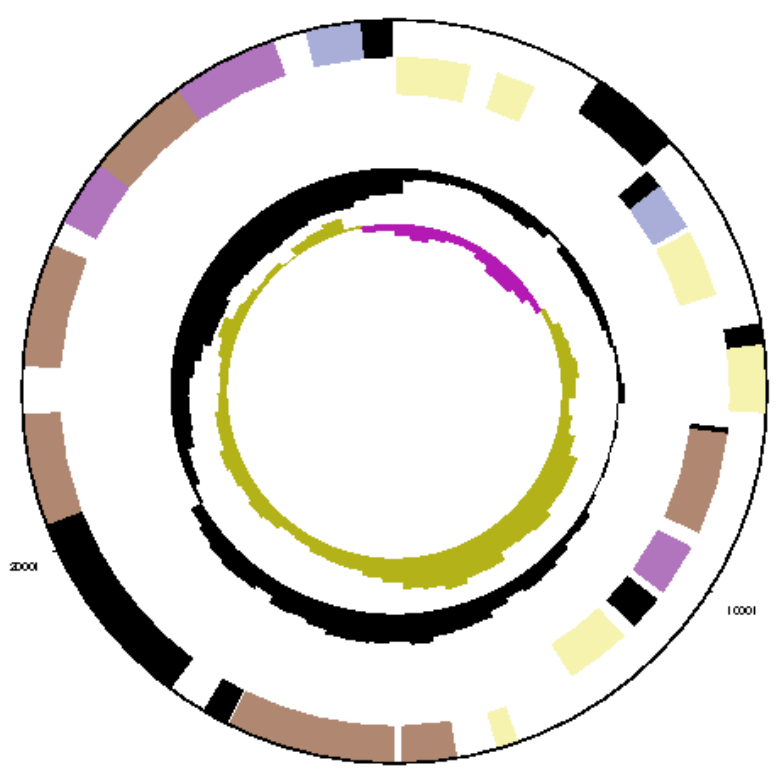

Figure 3f. Graphical map of the Phaeobacter arcticus DSM 23566 extrachromosomal element pArct_E29. From outside to the center: Genes on forward strand (color by COG categories), Genes on reverse strand (color by COG categories), RNA genes (tRNAs green, rRNAs red, other RNAs black), GC content, GC skew. 


\section{Insights into the genome}

The replication-initiation systems identified on the scaffolds were as follows: cArct_4215, dnaA; pArct_A280, repB-I; pArct_B229, repABC-5; pArct_C203, repABC-9; pArct_D92, repA-I; pArct_E29, repA-III, repA-IV and repB-III. This justifies the interpretation of cArct_4215 as (potentially circular) chromosome and of the other scaffolds as (potentially circular) extrachromosomal elements [36,37].

\section{Nitrogen metabolism}

Although it was reported that strain $20188^{\mathrm{T}}$ did not reduce nitrate [1], the enzymes required for nitrate reduction and metabolism of other nitrogen oxides are encoded in the genome of DSM $23566^{\mathrm{T}}$. The presence of nitrate reductase (narGHIJ, Phaar_00816 - Phaar_00819; nasA, Phaar_03836) and nitrite reductase (NAD $(\mathrm{P}) \mathrm{H})$ (nirBD; Phaar_03837, Phaar_03838) suggests the capacity for assimilatory nitrate reduction, i.e. reduction of nitrate via nitrite to ammonium [38]. Interestingly, only a copper-type nitrite reductase gene, analogous to nirK in $P$. gallaeciensis [39], is missing to complete the pathway for potential denitrification from nitrate to nitrogen. In addition to the above mentioned nitrate reductase genes, nitric oxide reductase (norBCDQ; Phaar_00646 - Phaar_00649) and, in contrast to $P$. gallaeciensis, even nitrous oxide reductase genes (nosDZ; Phaar_02837, Phaar_02838) are present, indicating the potential to reduce nitric oxide via nitrous oxide to nitrogen [40].

Small methylated amines are also considered as potential nitrogen source for many members of the marine Roseobacter clade [41]. In contrast to L. nanhaiensis DSM 24252 ${ }^{\mathrm{T}}$ (IMG object ID 2521172577), no methylamine-utilizing genes could be detected in $P$. arcticus strain DSM $23566^{\mathrm{T}}$, nor in $P$. gallaeciensis. When using the suggested protein sequences for trimethylamine monooxygenase (Tmm, ACK52489) and GMA synthetase (GmaS, BAF99006) [41] as query in the BLAST in the IMG database $[42,43]$ no hits $\left(\geq e^{-80}[44]\right.$,) were found. Lower e-value cutoffs ( $>$ e-30) yielded some hits but in contrast to methylamine-utilizing genes [41], these hits were not clustered together.

Although the strain did not grow with serine, Lglutamate or leucine as single substrate [1], L- serine dehydratase (EC:4.3.1.17, Phaar_02408) and threonine dehydratase (EC:4.3.1.19, Phaar_00247,_03532,_03664) genes, which catalyze the conversion of serine to pyruvate are found. The glutamate dehydrogenase (NAD(P)+) (EC:1.4.1.3, Phaar_00693) gene degrading Lglutamate to 2-oxoglutarate is also present in the genome sequence. However, we cannot exclude a putative lack of respective transport systems. For leucine degradation, all but one gene is present; dihydrolipoamide transacylase (EC:2.3.1.168). When using the respective protein sequence from the leucine utilizer Paracoccus denitrificans PD1222 as query through BLASTP, no hits were found in strain DSM 23566 ${ }^{\mathrm{T}}$. Interestingly, in $P$. daeponensis (IMG object ID 2521172619) which is known to grow with leucine, but also in $P$. caeruleus (IMG object ID 2512047087) the respective gene is located on an extrachromosomal element by which all genes of the leucine degradation pathway are found.

\section{Mobile genetic elements}

Genomic diversification of bacteria is known to be driven by phage-mediated horizontal gene transfer. Prophage-like structures are found in many (marine) bacteria $[45,46]$. In strain DSM 23566 ${ }^{\mathrm{T}}$, 58 genes were annotated as phage genes. This number is distinctly higher than those in the phylogenetically related Phaeobacter and Leisingera species (Figure 1; 8 - 38 phage genes) and in other Roseobacter clade bacteria [47]. Analysis of the genome of strain DSM 23566 ${ }^{\mathrm{T}}$ with PHAST [48] revealed eight prophage regions, two of which were intact, another four of which were questionable and two that were incomplete (Table $5)$. These prophage regions constituted nearly $5 \%$ of the bacterial chromosome (cArct_4215). One of the intact prophage regions (7) is likely a Mu-like phage, since many of the coding sequences (mostly corresponding to Phaar_02143 - Phaar_02190) yielded hits with Rhodobacter phage RcapMu (NC_016165), Enterobacteria phage $\mathrm{Mu}$ (NC_000929) and Burkholderia phage BcepMu (NC_005882). The incomplete prophage region 3 also had hits to $\mathrm{Mu}$-like phages. Mu-like phages are known to pack and transfer flanking host DNA in addition to their own genome and are found in Rhodobacter capsulatus, although they are more common in Gammaproteobacteria [49]. 
The other intact prophage region (region 4 in Table 5) strongly resembles a GTA (gene transfer agent) since it contains a major capsid protein (PhaarD_01806) that is similar $(64 \%, \mathrm{e}=0[42,43])$ to the highly conserved major capsid protein (g5) of $R$. capsulatus GTA [50,51]. These phage-like entities contain and transfer random fragments of bacterial host genomic DNA and are found in most
Alphaproteobacteria, especially in the Rhodobacterales [50]. The occurrence of all these prophage-like structures together with the absence of a CRISPR system (i.e. an antiphage defense system [52]) suggests that phages may be important for genomic diversification within the Phaeobacter group.

Table 4. Number of genes associated with the general COG functional categories

\begin{tabular}{crrl}
\hline Code & Value & \%age & Description \\
\hline J & 180 & 4.36 & Translation, ribosomal structure and biogenesis \\
A & 0 & 0 & RNA processing and modification \\
K & 326 & 7.89 & Transcription \\
L & 186 & 4.50 & Replication, recombination and repair \\
B & 2 & 0.05 & Chromatin structure and dynamics \\
D & 37 & 0.90 & Cell cycle control, cell division, chromosome partitioning \\
Y & 0 & 0 & Nuclear structure \\
V & 52 & 1.26 & Defense mechanisms \\
T & 161 & 3.90 & Signal transduction mechanisms \\
M & 207 & 5.01 & Cell wall/membrane/envelope biogenesis \\
N & 54 & 1.31 & Cell motility \\
Z & 1 & 0.02 & Cytoskeleton \\
W & 0 & 0 & Extracellular structures \\
U & 90 & 2.18 & Intracellular trafficking, secretion, and vesicular transport \\
O & 160 & 3.87 & Posttranslational modification, protein turnover, chaperones \\
C & 265 & 6.41 & Energy production and conversion \\
G & 180 & 4.36 & Carbohydrate transport and metabolism \\
E & 452 & 10.94 & Amino acid transport and metabolism \\
F & 82 & 1.98 & Nucleotide transport and metabolism \\
H & 177 & 4.28 & Coenzyme transport and metabolism \\
I & 292 & 7.07 & Lipid transport and metabolism \\
P & 186 & 4.50 & Inorganic ion transport and metabolism \\
Q & 161 & 3.90 & Secondary metabolites biosynthesis, transport and catabolism \\
\hline & 514 & 12.44 & General function prediction only \\
S & 367 & 8.88 & Function unknown \\
\hline & & & Not in COGs \\
\hline
\end{tabular}




\begin{tabular}{|c|c|c|c|c|c|c|c|}
\hline$\overline{\text { Region }}$ & Region Length & Completeness & Score & $\overline{C D S}$ & Region-Position & Specific Keyword & GC-\% \\
\hline 1 & $14.7 \mathrm{~Kb}$ & questionable & 70 & 18 & 3284-18065 & fiber, tail, head, lysin & $60.91 \%$ \\
\hline 2 & 22. $\mathrm{Kb}$ & incomplete & 50 & 22 & 1599730-1621795 & integrase, terminase & $58.75 \%$ \\
\hline 3 & $18.5 \mathrm{~Kb}$ & incomplete & 40 & 22 & $1804950-1823500$ & transposase & $55.77 \%$ \\
\hline 4 & $17.0 \mathrm{~Kb}$ & Intact & 100 & 20 & 1905214-1922300 & $\begin{array}{l}\text { capsid, fiber, tail, head, Portal, } \\
\text { terminase, protease }\end{array}$ & $62.27 \%$ \\
\hline 5 & $33.8 \mathrm{~Kb}$ & questionable & 90 & 37 & 2111516-2145342 & $\begin{array}{l}\text { integrase, tail, head, terminase, } \\
\text { lysin }\end{array}$ & \\
\hline & & & & & & & $59.92 \%$ \\
\hline 6 & $31.3 \mathrm{~Kb}$ & questionable & 70 & 25 & $2203367-2234719$ & integrase, tail, transposase & $57.69 \%$ \\
\hline 7 & $33.3 \mathrm{~Kb}$ & Intact & 110 & 46 & $2247246-2280565$ & $\begin{array}{l}\text { tail, plate, transposase, portal, } \\
\text { terminase, protease }\end{array}$ & \\
\hline 8 & $33.5 \mathrm{~Kb}$ & questionable & 90 & 19 & $2437800-2471330$ & $\begin{array}{l}\text { integrase, fiber, tail, head, } \\
\text { lysin }\end{array}$ & $\begin{array}{l}58.80 \% \\
60.17 \%\end{array}$ \\
\hline
\end{tabular}

+ COMPLETENESS, a prediction of whether the region contains an intact or incomplete prophage based on the applied criteria of PHAST; SCORE, the score of the region based on the applied criteria of PHAST; \#CDS, the number of coding sequence; REGION_POSITION, the start and end positions of the region on the bacterial chromosome; GC-\%, the percentage of GC nucleotides of the region.

\section{Secondary metabolism}

In contrast to its relative $P$. gallaeciensis, which is known for the production of the antibiotic tropodithietic acid (TDA) [39], no homologs of TDA production genes $t d a B C E F$ were found in strain DSM 23566'. However, Phaar_00595 shared homology $\left(\mathrm{e}<10^{-80}\right)$ with a lantibiotic biosynthesis protein LanM, and four genes (Phaar_00296, _00590,_01696, _01697) were homologous to bacteriocin/lantibiotic exporters indicating the production of peptide antibiotics $[53,54]$.

\section{Classification}

As the 16S rRNA gene analysis (Figure 1) indicated intermixed positions of Phaeobacter and Leisingera species (even though with low bootstrap support), the classification of the group might need to be reconsidered. We thus conduct- ed a preliminary phylogenomic analysis using GGDC [55-57] and the draft genomes of the type strains of the other Leisingera and Phaeobacter species. The results shown in Table 6 indicate that the DNA-DNA hybridization (DDH) similarities calculated in silico of $P$. articus to other Phaeobacter species are, on average, not higher than those to Leisingera species. The highest value is actually obtained for L. nanhaiensis and formula 2 , which is preferred if genomes are only incompletely sequenced [55]. The overall low similarity values indicate that $P$. arcticus might better be placed in a separate genus, particularly if compared to the according similarity values between the other Leisingera and Phaeobacter species $[58,59]$. 
Table 6. DDH similarities between $P$. arcticus DSM $23566^{\top}$ and the other Phaeobacter and Leisingera species (with genome-sequenced type strains) calculated in silico with the GGDC server version 2.0 [55].

\begin{tabular}{lccr}
\hline Reference species & formula 1 & formula 2 & formula 3 \\
\hline L. aquamarina (2521172617) & $16.60 \pm 3.25$ & $20.70 \pm 2.32$ & $16.50 \pm 2.75$ \\
L. methylohalidivorans (2512564009) & $17.20 \pm 3.28$ & $20.40 \pm 2.32$ & $17.00 \pm 2.77$ \\
L. nanhaiensis (2521172577) & $14.60 \pm 3.12$ & $22.90 \pm 2.37$ & $14.80 \pm 2.66$ \\
P. caeruleus (2512047087) & & & \\
P. daeponensis (2521172619) & $16.90 \pm 3.26$ & $20.40 \pm 2.32$ & $16.70 \pm 2.76$ \\
& & & \\
P. gallaeciensis (AOQA01000000) & $17.00 \pm 3.27$ & $21.00 \pm 2.33$ & $16.90 \pm 2.77$ \\
& & & $16.40 \pm 2.75$ \\
P. inhibens (2516653078) & $16.40 \pm 3.24$ & $21.80 \pm 2.35$ & \\
\hline
\end{tabular}

The standard deviations indicate the inherent uncertainty in estimating DDH values from intergenomic distances based on models derived from empirical test data sets (which are always limited in size); see [57] for details. The distance

\section{Acknowledgements}

The authors would like to gratefully acknowledge the assistance of Iliana Schröder for growing P. arcticus cultures and Evelyne-Marie Brambilla for DNA extraction and quality control (both at the DSMZ). The work conducted by the U.S. Department of Energy Joint Genome Institute was supported by the Office of Science

\section{References}

1. Zhang DC, Li HR, Xin YH, Liu HC, Chi ZM, Zhou PJ, Yu Y. Phaeobacter arcticus sp. nov., a psychrophilic bacterium isolated from the Arctic. Int J Syst Evol Microbiol 2008; 58:1384-1387. PubMed http://dx.doi.org/10.1099/ijs.0.65708-0

2. Altschul SF, Gish W, Miller W, Myers EW, Lipman DJ. Basic Local Alignment Search Tool. J Mol Biol 1990; 215:403-410. PubMed

3. Korf I, Yandell M, Bedell J. BLAST, O'Reilly, Sebastopol, 2003. formulas are explained in [55]. The numbers in parentheses are IMG object IDs (GenBank accession number in the case of $P$. gallaeciensis) identifying the underlying genome sequences.

of the U.S. Department of Energy under contract No. DE-AC02-05CH11231; the work conducted by the members of the Roseobacter consortium was supported by the German Research Foundation (DFG) Transregio-SFB 51.

4. DeSantis TZ, Hugenholtz $P$, Larsen $N$, Rojas $M$, Brodie EL, Keller K, Huber T, Dalevi D, Hu P, Andersen GL. Greengenes, a chimera-checked 16S rRNA gene database and workbench compatible with ARB. Appl Environ Microbiol 2006; 72:5069-5072. PubMed http://dx.doi.org/10.1128/AEM.03006-05

5. Porter MF. An algorithm for suffix stripping. Program: electronic library and information systems 1980; 14: 130-137. 
6. Lee C, Grasso C, Sharlow MF. Multiple sequence alignment using partial order graphs. Bioinformatics 2002; 18:452-464. PubMed http://dx.doi.org/10.1093/bioinformatics/18.3.452

7. Castresana J. Selection of conserved blocks from multiple alignments for their use in phylogenetic analysis. Mol Biol Evol 2000; 17:540-552. PubMed

http://dx.doi.org/10.1093/oxfordjournals.molbev.a $\underline{026334}$

8. Stamatakis A, Hoover $\mathrm{P}$, Rougemont J. A rapid bootstrap algorithm for the RaxML web servers. Syst Biol 2008; 57:758-771. PubMed http://dx.doi.org/10.1080/10635150802429642

9. Pattengale ND, Alipour M, Bininda-Emonds ORP, Moret BME, Stamatakis A. How many bootstrap replicates are necessary? Lect Notes Comput Sci 2009; 5541:184-200. http://dx.doi.org/10.1007/978-3-642-02008-7_13

10. Swofford DL. PAUP*: Phylogenetic Analysis Using Parsimony (*and Other Methods), Version 4.0 b10, Sinauer Associates, Sunderland, 2002.

11. Pagani I, Liolios K, Jansson J, Chen IM, Smirnova T, Nosrat B, Markowitz VM, Kyrpides NC. The Genomes OnLine Database (GOLD) v.4: status of genomic and metagenomic projects and their associated metadata. Nucleic Acids Res 2012;

40:D571-D579. PubMed http://dx.doi.org/10.1093/nar/gkr1100

12. Thrash JC, Cho JC, Vergin KL, Giovannoni SJ. Genome sequences of Oceanicola granulosus HTCC2516T and Oceanicola batsensis HTCC2597' . J Bacteriol 2010; 192:3549-3550. PubMed http://dx.doi.org/10.1128/JB.00412-10

13. Field D, Garrity G, Gray T, Morrison N, Selengut J, Sterk P, Tatusova T, Thomson N, Allen MJ, Angiuoli SV, et al. The minimum information about a genome sequence(MIGS) specification. Nat Biotechnol 2008; 26:541-547. PubMed http://dx.doi.org/10.1038/nbt1360

14. Woese CR, Kandler O, Wheelis ML. Towards a natural system of organisms: proposal for the domains Archaea, Bacteria, and Eucarya. Proc Natl Acad Sci USA 1990; 87:4576-4579. PubMed http://dx.doi.org/10.1073/pnas.87.12.4576

15. Garrity GM, Bell JA, Lilburn T. Phylum XIV. Proteobacteria phyl. nov. In: Garrity GM, Brenner DJ, Krieg NR, Staley JT (eds), Bergey's Manual of Systematic Bacteriology, Second Edition, Volume 2, Part B, Springer, New York, 2005, p. 1.
16. Validation List No. 107. List of new names and new combinations previously effectively, but not validly, published. Int I Syst Evol Microbiol 2006; 56:1-6. PubMed http://dx.doi.org/10.1099/ijs.0.64188-0

17. Garrity GM, Bell JA, Lilburn T. Class I. Alphaproteobacteria class. nov. In: Garrity GM, Brenner DJ, Krieg NR, Staley JT (eds), Bergey's Manual of Systematic Bacteriology, Second Edition, Volume 2, Part C, Springer, New York, 2005, p. 1.

18. Garrity GM, Bell JA, Lilburn T. Order III. Rhodobacterales ord. nov. In: Garrity GM, Brenner DJ, Krieg NR, Staley JT (eds), Bergey's Manual of Systematic Bacteriology, Second Edition, Volume 2, Part C, Springer, New York, 2005, p. 161.

19. Garrity GM, Bell JA, Lilburn T. Family I. Rhodobacteraceae fam. nov. In: Garrity GM, Brenner DJ, Krieg NR, Staley JT (eds), Bergey's Manual of Systematic Bacteriology, Second Edition, Volume 2, Part C, Springer, New York, 2005, p. 161.

20. Martens T, Heidorn T, Pukall R, Simon M, Tindall BJ \& Brinkhoff T. Reclassification of Roseobacter gallaeciensis Ruiz-Ponte et al. 1998 as Phaeobacter gallaeciensis gen.nov., comb. nov., description of Phaeobacter inhibens sp. nov., reclassification of Ruegeria algicola (Lafay et al. 1995) Uchino et al. 1999 as Marinovum algicola gen.nov., comb. nov., and emended descriptions of the genera Roseobacter, Ruegeria and Leisingera. Int J Syst Evol Microbiol 2006; 56:1293-1304. PubMed http://dx.doi.org/10.1099/ijs.0.63724-0

21. Yoon JH, Kang SJ, Lee SY, Oh TK. Phaeobacter daeponensis sp. nov., isolated from a tidal flat of the Yellow Sea in Korea. Int I Syst Evol Microbiol 2007; 57:856-861. PubMed http://dx.doi.org/10.1099/ijs.0.64779-0

22. http://www.baua.de/ BAuA. 2010, Classification of bacteria and archaea in risk groups. TRBA 466, p. 168.

23. List of growth media used at DSMZ: http://www.dsmz.de/catalogues/cataloguemicroor ganisms/culture-technology/list-of-media-formicroorganisms.html

24. Gemeinholzer B, Droge G, Zetzsche H, Haszprunar G, Klenk HP, Guntsch A, Berendsohn WG, Wagele JW. The DNA Bank Network: the start from a German initiative. Biopreserv Biobank 2011; 9:51-55. http://dx.doi.org/10.1089/bio.2010.0029 
25. Bennett S. Solexa Ltd. Pharmacogenomics 2004; 5:433-438. PubMed http://dx.doi.org/10.1517/14622416.5.4.433

26. The DOE Joint Genome Institute. http://www.jgi.doe.gov

27. Butler J, MacCallum I, Kleber M, Shlyakhter IA, Belmonte MK, Lander ES, Nusbaum C, Jaffe DB. ALLPATHS: de novo assembly of whole-genome shotgun microreads. Genome Res 2008; 18:810820. PubMed http://dx.doi.org/10.1101/gr.7337908

28. Zerbino DR, Birney E. Velvet: Algorithms for de novo short read assembly using de Bruijn graphs. Genome Res 2008; 18:821-829. PubMed http://dx.doi.org/10.1101/gr.074492.107

29. Ewing B, Green P. Base-calling of automated sequencer traces using phred. II. Error probabilities. Genome Res 1998; 8:175-185. PubMed http://dx.doi.org/10.1101/gr.8.3.175

30. Ewing B, Hillier L, Wendl MC, Green P. Basecalling of automated sequencer traces using phred. I. Accuracy assessment. Genome Res 1998; 8:175-185. PubMed http://dx.doi.org/10.1101/gr.8.3.175

31. Gordon D, Abajian C, Green P. Consed: a graphical tool for sequence finishing. Genome Res

1998; 8:195-202. PubMed http://dx.doi.org/10.1101/gr.8.3.195

32. Hyatt $D$, Chen GL, LoCascio PF, Land ML, Larimer FW, Hauser LJ. Prodigal: Prokaryotic gene recognition and translation initiation site identification. BMC Bioinformatics 2010; 11:119. PubMed http://dx.doi.org/10.1186/1471-2105-11-119

33. Mavromatis K, Ivanova NN, Chen IM, Szeto E, Markowitz VM, Kyrpides NC. The DOE-JGI Standard operating procedure for the annotations of microbial genomes. Stand Genomic Sci 2009; 1:63-67. PubMed http://dx.doi.org/10.4056/sigs.632

34. Pati A, Ivanova NN, Mikhailova N, Ovchinnikova G, Hooper SD, Lykidis A, Kyrpides NC. GenePRIMP: A gene prediction improvement pipeline for prokaryotic genomes. Nat Methods 2010; 7:455-457. PubMed http://dx.doi.org/10.1038/nmeth.1457

35. Markowitz VM, Mavromatis K, Ivanova NN, Chen IMA, Chu K, Kyrpides NC. IMG ER: A system for microbial genome annotation expert review and curation. Bioinformatics 2009; 25:2271-2278. PubMed http://dx.doi.org/10.1093/bioinformatics/btp393
36. del Solar G, Giraldo R, Ruiz-Echevarria MJ, Espinosa M, Diaz-Orejas R. Replication and control of circular bacterial plasmids. Microbiol Mol Biol Rev 1998; 62:434-464. PubMed

37. Petersen J. Phylogeny and compatibility: Plasmid classification in the genomics era. Arch Microbiol 2011; 193:313-321. PubMed

38. Malm S, Tiffert $Y$, Micklinghoff J, Schultze $S$, Joost I, Weber I, Horst S, Ackermann B, Schmidt M, Wohlleben $\mathrm{W}$, et al. The roles of the nitrate reductase NarGHJI, the nitrite reductase NirBD and the response regulator $\mathrm{G} \ln \mathrm{R}$ in nitrate assimilation of Mycobacterium tuberculosis. Microbiology 2009; 155:1332-1339. PubMed http://dx.doi.org/10.1099/mic.0.023275-0

39. Thole S, Kalhoefer D, Voget S, Berger M, Engelhardt T, Liesegang $\mathrm{H}$, Wollherr A, Kjelleberg S, Daniel R, Simon M, et al. Phaeobacter gallaeciensis genomes from globally opposite locations reveal high similarity of adaptation to surface life. ISME J 2012; 6:2229-2244. PubMed http://dx.doi.org/10.1038/ismej.2012.62

40. Rodionov DA, Dubchak IL, Arkin AP, Alm EJ, Gelfand MS. Dissimilatory metabolism of nitrogen oxides in bacteria: Comparative reconstruction of transcriptional networks. PLOS Comput Biol 2005; 1:e55. PubMed http://dx.doi.org/10.1371/journal.pcbi.0010055

41. Chen Y. Comparative genomics of methylated amine utilization by marine Roseobacter clade bacteria and development of functional gene markers (tmm, gmaS). Environ Microbiol 2012. PubMed http://dx.doi.org/10.1111/j.14622920.2012.02765.x

42. Altschul SF, Madden TL, Schaffer AA, Zhang J, Zhang Z, Miller W, Lipman DJ. Gapped BLAST and PSI-BLAST: A new generation of protein database search programs. Nucleic Acids Res 1997; 25:3389-3402. PubMed http://dx.doi.org/10.1093/nar/25.17.3389

43. Altschul SF, Wootton JC, Gertz EM, Agarwala R, Morgulis A, Schaffer AA, Yu YK. Protein database searches using compositionally adjusted substitution matrices. FEBS / 2005; 272:5101-5109. PubMed http://dx.doi.org/10.1111/j.17424658.2005.04945.x

44. Chen Y, Patel NA, Crombie A, Scrivens JH, Murrell JC. Bacterial flavin-containing monooxygenase is trimethylamine monooxygenase. Proc Natl Acad Sci USA 2011; 108:17791-17796. PubMed http://dx.doi.org/10.1073/pnas.1112928108 
45. Canchaya C, Proux C, Fournous G, Bruttin A. Prophage genomics. Microbiol Mol Biol Rev 2003; 67:238-276. PubMed http://dx.doi.org/10.1128/MMBR.67.2.238276.2003

46. Paul JH. Prophages in marine bacteria: dangerous molecular time bombs or the key to survival in the seas? ISME J 2008; 2:579-589. PubMed http://dx.doi.org/10.1038/ismej.2008.35

47. Newton RJ, Griffin LE, Bowles KM, Meile C, Gifford S, Givens CE, Howard EC, King E, Oakley CA, Reisch CR, et al. Genome characteristics of a generalist marine bacterial lineage. ISME J 2010; 4:784-798. PubMed http://dx.doi.org/10.1038/ismej.2009.150

48. Zhou Y, Liang Y, Lynch KH, Dennis JJ, Wishart DS. PHAST: A fast phage search tool. Nucleic Acids Res 2011; 39:W347-W352. PubMed http://dx.doi.org/10.1093/nar/gkr485

49. Fogg PCM, Hynes AP, Digby E, Lang AS, Beatty JT. Characterization of a newly discovered Mulike bacteriophage, RcapMu, in Rhodobacter capsulatus strain SB1003. Virology 2011;

421:211-221. PubMed http://dx.doi.org/10.1016/j.virol.2011.09.028

50. Lang AS, Beatty JT. Importance of widespread gene transfer agent genes in alphaproteobacteria. Trends Microbiol 2007; 15:54-62. PubMed http://dx.doi.org/10.1016/j.tim.2006.12.001

51. Zhao YL, Wang K, Budinoff C, Buchan A, Lang A, Jiao NZ, Chen F. Gene transfer agent (GTA) genes reveal diverse and dynamic Roseobacter and Rhodobacter populations in the Chesapeake Bay. ISME J 2009; 3:364-373. PubMed http://dx.doi.org/10.1038/ismej.2008.115

52. Koonin EV, Wolf YI. Is evolution Darwinian or/and Lamarckian? Biol Direct 2009; 4:42. PubMed http://dx.doi.org/10.1186/1745-6150-4-42

53. Bierbaum G, Sahl HG. Lantibiotics: Mode of action, biosynthesis and bioengineering. Curr Pharm
Biotechnol 2009; 10:2-18. PubMed

http://dx.doi.org/10.2174/138920109787048616

54. O'Sullivan O, Begley M, Ross RP, Cotter PD, Hill C. Further Identification of novel lantibiotic operons using LanM-based genome mining. Probiotics and Antimicrobial Proteins 2011; 3:27-40. http://dx.doi.org/10.1007/s12602-011-9062-y

55. Auch AF, Klenk HP, Goker M. Standard operating procedure for calculating genome to genome distances based on high-scoring segment pairs. Stand Genomic Sci 2010; 2:142-148. PubMed http://dx.doi.org/10.4056/sigs.541628

56. Auch AF, Von Jan M, Klenk HP, Goker M. Digital DNA-DNA hybridization for microbial species delineation by means of genome-to-genome sequence comparison. Stand Genomic Sci 2010; 2:117-134. PubMed http://dx.doi.org/10.4056/sigs.531120

57. Meier-Kolthoff JP, Auch AF, Klenk HP, Goker M. Genome sequence-based species delimitation with confidence intervals and improved distance functions. BMC Bioinformatics 2013; 14: 60.

58. Riedel T, Teshima H, Petersen J, Fiebig A, Davenport K, Dalingault H, Erkkila T, Gu W, Munk C, $\mathrm{Xu} \mathrm{Y}$, et al. Genome sequence of the Leisingera aquimarina type strain (DSM $24565^{\mathrm{T}}$ ), a member of the Roseobacter clade rich in extrachromosomal elements. Stand Genomic Sci 2013; 8:389-402.

59. Beyersmann PG, Chertkov O, Petersen J, Fiebig A, Chen A, Pati A, Ivanova N, Lapidus A, Goodwin LA, Chain P, et al. Genome sequence of Phaeobacter caeruleus type strain (DSM 24564T), a surface-associated member of the marine Roseobacter clade. Stand Genomic Sci 2013; 8:x.

60. Ashburner M, Ball CA, Blake JA, Botstein D, Butler $\mathrm{H}$, Cherry JM, Davis AP, Dolinski K, Dwight SS, Eppig JT, et al. Gene ontology: Toolfor the unification of biology. Nat Genet 2000; 25:25-29. $\underline{\text { PubMed http://dx.doi.org/10.1038/75556 }}$ 